\title{
INVESTIGATION OF USING NATURAL AROMATIZERS OF LEMON ESSENTIAL OIL IN AYURVEDIC CULINARY
}

\author{
Natalya Frolova \\ Department of Technology of Restaurant and Ayurvedic Products \\ National University of Food Technologies \\ 68 Volodymyrska str., Kyiv, Ukraine, 01601 \\ frolovan809@gmail.com \\ Iryna Sylka \\ Department of Technology of Restaurant and Ayurvedic Products \\ National University of Food Technologies \\ 68 Volodymyrska str., Kyiv, Ukraine, 01601 \\ irinasilka@ukr.net \\ Aleksandra Nemirich \\ Department of Technology of Restaurant and Ayurvedic Products \\ National University of Food Technologies \\ 68 Volodymyrska str., Kyiv, Ukraine, 01601 \\ nemirichav@gmail.com \\ Oleg Kuzmin \\ Department of Technology of Restaurant and Ayurvedic Products \\ National University of Food Technologies \\ 68 Volodymyrska str., Kyiv, Ukraine, 01601 \\ kuzmin_ovl@ukr.net
}

\begin{abstract}
There was considered a possibility of using natural aromatizers in ayurvedic culinary, namely fractions that act as a product of lemon essential oil. There was presented the component ratio and characteristic of a fragrance of a terpene fraction and terpenoid one, obtained by the gas-chromatographic analysis on a nozzle column with a stable dynonyl phthalate fraction by the standard method.

A classic salad sauce "Vinaigrette" was chosen as a research subject. The introduction of natural aromatizers was conducted at the final stage of mixing olive oil and other ingredients of the dish. The optimal amount of aromatizers was determined empirically by sensor analysis results. During the studies, it has been established, that a fraction of lemon essential oil No. 1 must be introduced in amount $0,1 \mathrm{~g}$ for $1000 \mathrm{~g}$ of the ready product, a fraction of lemon essential oil No. $2-0,125 \mathrm{~g}$ for $1000 \mathrm{~g}$ of the ready product.

As far as terpenes and terpenoids of lemon essential oil are natural substances of the initial raw material, stimulating food juices extraction, it allows to state about the activation of so-called "digestive fire" at using the aromatized sauce.
\end{abstract}

Keywords: lemon essential oil, aromatizer, faction, ayurvedic culinary, salad sauce "Vinaigrette".

\section{Introduction}

Ayurvedic culinary is a section, studied by ayurveda, first mentioned more than 5000 years. It studied a large number of directions: vastu shastra, ayurvedic approach to medicine, mathematics and so on [1]. In the same way, ayurveda studies nutrition, based on the doctrine about the influence of food products on the human organism.

For Western countries dwellers the most topical principle, among ones, studied by ayurveda is in paying the special attention to the cooked food freshness. According to ayurvedic traditions, if a human suffers from the lack of energy, internal uncertainty, diseases or depression, it is better for him/her to reject fast-food, yesterday's meal, canned or frozen food [2].

Many modern establishments of the Ukrainian restaurant economy pose themselves as vegetarian ones and offer the wide assortment of ayurvedic dishes, which special part is sauces. It is an 
additional component of a dish of semi-liquid consistence, used in the cooking process or given for improving its taste, smell and outlook.

Ancient sauce traditions of India and China more and more often attract attention of European chefs. Today in Ukraine there is observed a tendency to elaborating a technology of "lighter" sauces with a high content of functional substances [3]. But their specific weight remains unessential, although they are demanded by a consumer.

That is why a promising direction is the development of new types of sauces, including vegetable raw materials with functional properties. These techniques allow to widen the assortment of sauces, to improve their color, to decrease the energetic value, to diminish the price. But it is impossible to make modern high-quality competitive products without the additional introduction of aromatic substances that allow:

- to create the wide assortment of food products, based on products of the same kind (caramel, jelly, ice-cream, alcohol-free and low-alcohol drinks, yoghurts, chewing gums and so on);

- to intensify a natural taste and smell, typical for this product;

- to add a smell to products with a high food value, but without a smell (soya processing products);

- to aromatize products, which technologies don't provide the natural creation of a smell;

- to deprive food products of tastes, unpleasant for a consumer.

The modern food industry just cannot be imagined without aromatizers, because it is connected with thousand-year traditions to give special taste and smells to cooked dishes. And if talk about ayurvedic culinary, saturated with spices and flavorings, aromatizers are its unalienable part. At that it must be noted, that all ingredients of ayurvedic food must be obligatory natural.

This category by right includes natural aromatizers that are chemical compounds, separated by physical processes (including distillation and extraction) from materials of the natural origin. Spices and essential oils relate to them.

Ayurveda considers aromatic substances as important food components, improving digestion at the expanse of activating so-called "digestive fire" and as a result improving the process of food digestion and assimilation. Terpenes and terpenoids, extracted from vegetable raw materials, have the essential intensity of a smell, constant quality parameters, stimulate appetite and can be completely used as aromatizers.

The aim of the work is to add the additional smell to the salad sauce by using fractions of lemon essential oil, in such a way widening the assortment of sauces with stable characteristics.

\section{Materials and Methods}

The classic salad sauce "Vinaigrette" was chosen as a research subject: it is easily cooked, healthy, tasty and cheap [4]. The word "vinaigrette" or "sauce vinaigrette" means vinegar in French. In ayurvedic culinary it may be added to dishes, that, for example, Americans eat with ketchup. That is why it is possible to infuse stably high organoleptic parameters at using fractions of lemon essential oil as a natural aromatizer.

The sauce "vinaigrette" was used for the salad, according to the traditional recipe No. 603 [4]. For cooking this sauce, vegetable oil, vinegar and salt must be mixed. The received mixture is just the most basic vinaigrette, on which base liquid sauces for salads with different organoleptic properties were obtained, adding natural aromatizers of deterpenized lemon essential oil.

The qualitative and quantitative composition of essential oil and its fractions was studied by the method of gas-chromatographic analysis of raw materials and products of aromatizers' technology on a nozzle column with the stable phase of $20 \%$ dynonil phthalate [5].

\section{Experimental procedures}

\subsection{The analysis of fractions of lemon essential oil}

The technology of creating an aromatized product with high competitiveness parameters provides the selection of an aromatizer concentration. For creating new aromatized sauces with a spicy and citrus direction of a smell, fractions of deterpenized lemon essential oil were used. 
An advantage of using a nozzle column in this study is a possibility to introduce a sample in amount $5 . .10 \mathrm{mcl}$ in a chromatograph.

Research results prove the effectiveness of separating terpene carbohydrates with extracting a terpenes fraction (including limonene) and terpenoids one that is more than $60 \%$ of the total composition of lemon essential oil. The obtained data, presented in Table 1, favor the prognostication of a fraction smell at developing the sauce recipe.

Table 1

Qualitative composition and quantitative ratios of components of lemon essential oil fractions

\begin{tabular}{|c|c|c|c|}
\hline \multicolumn{2}{|c|}{ Fraction No. 1} & \multicolumn{2}{|c|}{ Fraction No. 2} \\
\hline Component & Amount, $\%$ & Component & Amount, $\%$ \\
\hline$\alpha$-pinene & 2,30 & citral & 20,28 \\
\hline$\beta$-myrcene & 5,12 & 1-linalool & 17,36 \\
\hline \multirow[t]{2}{*}{ d-limonene } & 80,0 & geraniol & 14,75 \\
\hline & & d-limonene & 42,00 \\
\hline
\end{tabular}

The use of reliable data of a smell of essential oil components in the industrial production is a guarantee of creating different aromatic compositions with stable characteristics.

The fraction of terpenes No. 1 has the lemon smell, and its content of $\beta$-myrcene adds a tint of bergamot. Citral in the fraction of terpenoids No. 2 adds a muscat tone in the smell that together with geraniol and linalool acquires a noble smell of citruses with a tint of flowers.

\section{2. The choice of the optimal amount of fractions of deterpenized lemon essential oil} in the salad sauce

According to normative documents, it is recommended to use natural aromatizers with solutions with a mass share of the high-concentrated base from $0,1 \%$ to $98,0 \%$ [6]. But it is necessary to note, that the high-concentrated base of an aromatizer has the high solubility degree also in hydrophobic solvents.

The choice of a solvent type and selection of the mass share of the base for an aromatizer were realized by the empirical way for reaching high organoleptic indices of the aromatized food product. Based on it, the mixture of olive oil and aromatizer was created at mass ratio 10:1.

Preparing the sauce "vinaigrette", it must be remembered: for making the mixture heterogenic, it is necessary to shake it by a whisk or energetically shake in the closed crockery. This sauce is prepared directly before putting on a table, because already in several minutes after cooking, oil and vinegar begin to flake.

The following step is the complex evaluation of the quality of aromatized sauces for salads. As it is testified by literary data [8], organoleptic evaluation methods allow to make a rather distinct conclusion about the product quality and don't need an expensive equipment and devices. Organoleptic parameters include: taste, smell and consistence. Investigating different amounts of the introduced aromatizer by the sensor method, there were determined the smell intensity of the ready product and its organoleptic parameters.

The essence of this method was in comparing of experimental samples with different amounts of the aromatizer with the basic sauce sample without aromatizers (control), which intensity was accepted as 0 points, and quality parameters as 2 points by the five-point system.

At increasing the amount of the aromatizer, the smell intensity increases too, that favors more expressiveness of all organoleptic parameters. But the further increase of the amount of aromatizers, on the contrary, worsens all organoleptic parameters, namely: the aromatizer's smell and not sauce one prevails, the bitterish smack appears and the consistence worsens. The mean values of these parameters are presented as the quality evaluation (Table 2).

Fig. 1 presents results of the sensor studies of the sauces with different amounts of the lemon essential oil fraction No. 1 within $0.01 \ldots .0,035 \%$. 
Table 2

Evaluation of the salad sauce quality adding the lemon essential oil fraction No. 1

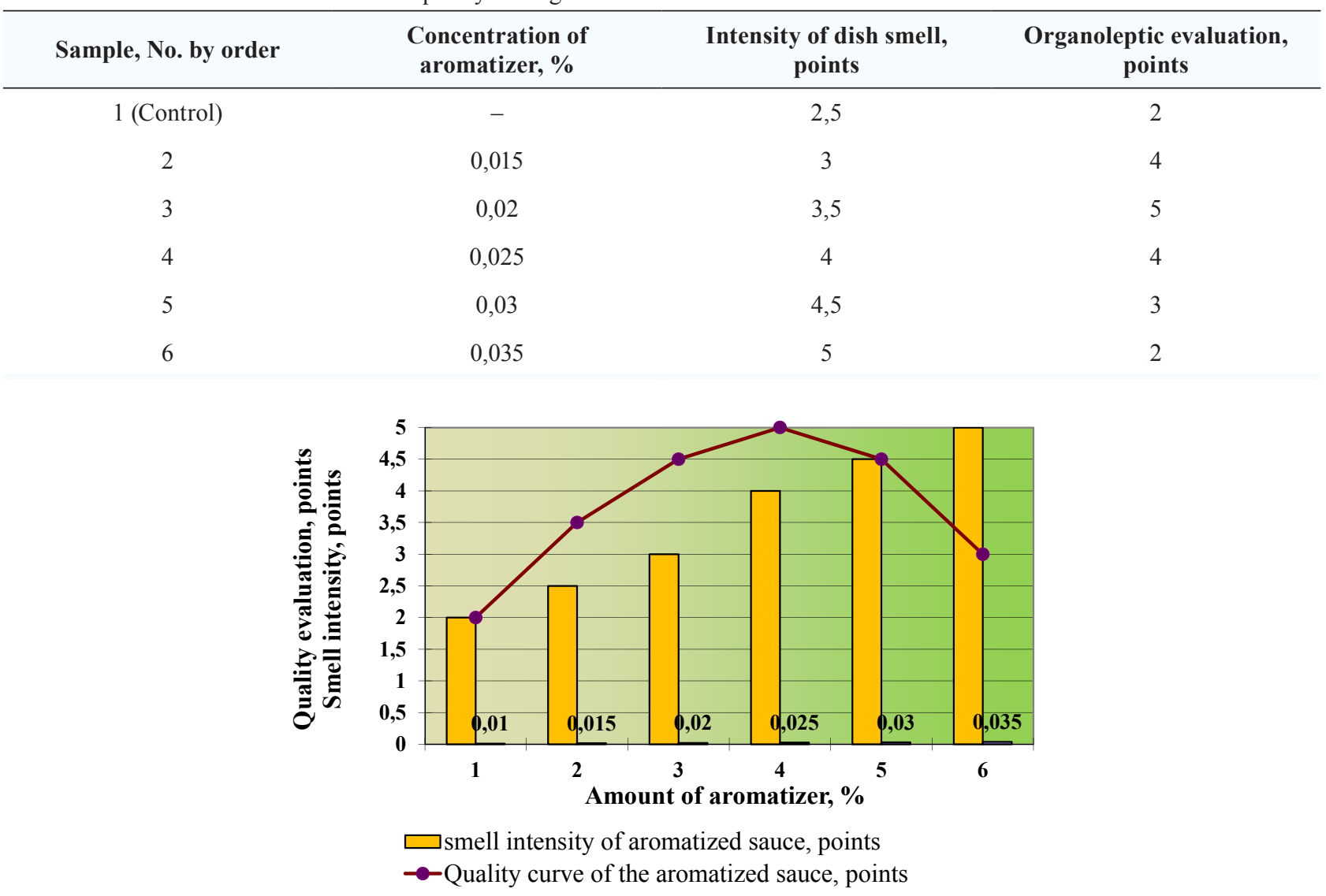

Fig. 1. Sensor evaluation of the quality of the aromatized sauce No. 1

On the graph we can observe intensifications of the smell, from which it is concluded about the direct dependence between the amount of the introduced fraction of terpenoids and sauce smell intensity.

The study of the optimal amount of the lemon essential oil fraction No. 2 was conducted analogously. The results of the work are presented in Table 3.

Table 3

Evaluation of the salad sauce quality adding the lemon essential oil fraction No. 2

\begin{tabular}{cccc}
\hline Sample, No. by order & $\begin{array}{c}\text { Concentration of aromatizer, } \\
\%\end{array}$ & $\begin{array}{c}\text { Intensity of dish smell, points } \\
\text { points }\end{array}$ & $\begin{array}{c}\text { Organoleptic evaluation, } \\
\text { points }\end{array}$ \\
\hline 1 (Control) & - & 2 & 2 \\
2 & 0,015 & 2,5 & 3,5 \\
3 & 0,02 & 3 & 4,5 \\
4 & 0,025 & 4,5 & 4,5 \\
6 & 0,03 & 5 & 3
\end{tabular}

The sensor evaluation of experimental samples with introducing the faction No. 2 is visually presented on Fig. 2. At the continuous growth of the smell intensity, there is also observed the abrupt worsening of the ready product quality. 


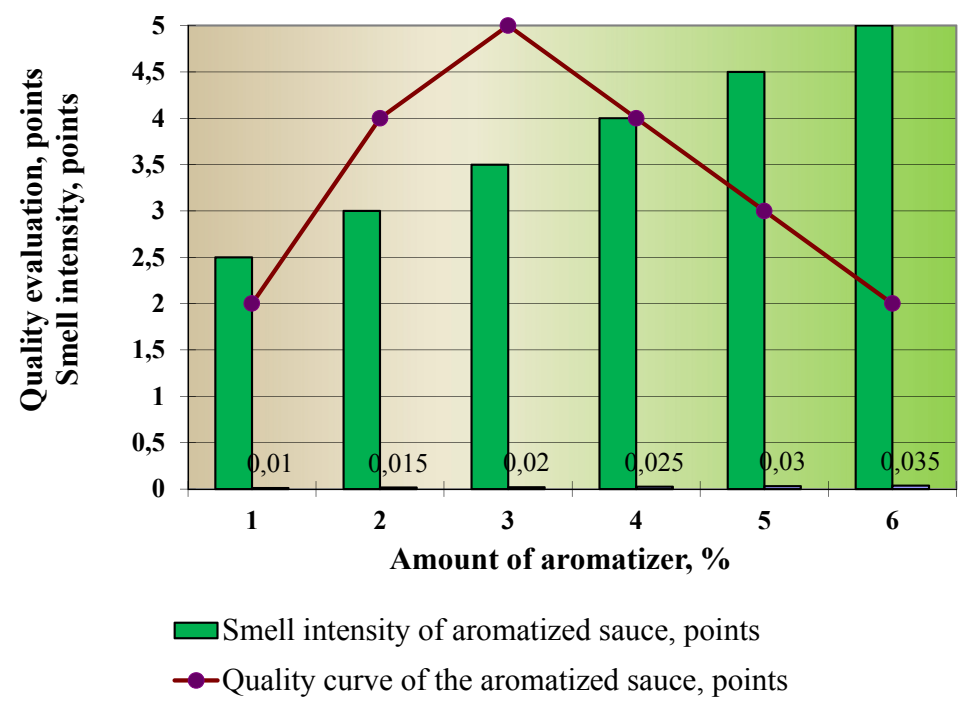

Fig. 2. Sensor evaluation of the quality of the aromatized sauce No. 2

The curve, presenting organoleptic properties of dishes has a hyperbolic character and testifies that the optimal amount of introduction is $0,02 \%$ of the fraction No. 1 and $0,025 \%$ of the fraction No. 2 of lemon essential oil.

According to the research results, there was developed the recipe of the sauce for salads in ayurvedic culinary (Table 4).

Table 4

Recipe of the sauce for salads

\begin{tabular}{ccc}
\hline Raw material & Raw material mass, $\mathbf{g}$ & Raw material mass, $\mathbf{g}$ \\
\hline Corn oil & 475 & 475 \\
Olive oil & 25 & 25 \\
Fraction No. 1 & 0,1 & 0,125 \\
Fraction No. 2 & - & 500 \\
$3 \%$-vinegar & 500 & 40 \\
Sugar & 40 & 20 \\
Salt & 20 & 1000,0
\end{tabular}

According to the recipe, it must be introduced $0,1 \mathrm{~g}$ of the fraction No. 1 and $0,125 \mathrm{~g}$ of the fraction No. 2 of lemon essential oil, that are high-concentrated aromatizers, for one $\mathrm{kg}$ of the ready product.

\section{3. The investigation of taste-aromatic properties}

The investigation of taste-aromatic properties of the aromatized sauces for salads was conducted by comparing their characteristics with the basic product. Based on literary data [9, 10], there were used 10 smell descriptors that describe feelings, caused by the product, most distinctly (Table 5).

The quality evaluation and characterization of the smell was conducted by determining its quality, intensity, presence of special tints. The smell intensity was characterized by the fivepoint scale. Based on the results, obtained at processing the ones of the sensor analysis, there were constructed the profilograms of the basic product and aromatized sauces with introducing lemon essential oil fractions (Fig. 3). 
Table 5

Characteristics of smell descriptors

\begin{tabular}{|c|c|}
\hline Descriptor & Character \\
\hline Cream & Fragrance of pasteuri \\
\hline Lemon & Smell of le \\
\hline Fresh & Smell without perceive \\
\hline Oily & Smell of oil, included in th \\
\hline Sour & Perceived smell of \\
\hline Muscat & Pleasant fragranc \\
\hline Acute & Intensive, inhibiting c \\
\hline Rancid & Unpleasant smell \\
\hline Bad fat & Smell of spoi \\
\hline Stable & Fragrance, stay \\
\hline rancid & $\begin{aligned} \rightarrow & \text { Base product } \\
\rightarrow & \text { Sauce for salads with } \\
& \text { introducing fraction } 1 \\
- & \text { Sauce for salads with } \\
& \text { introducing fraction } 2\end{aligned}$ \\
\hline
\end{tabular}

Fig. 3. Comparative profilogram of the basic product and aromatized sauces for salads

The additional introduction of natural aromatizers allows to raise organoleptic characteristics that is testified by the results of the complex quality evaluation. The introduction of natural aromatizers of essential oils provides the complete independence of a dish on season and complete reproducibility of its smell.

According to ayurvedic principles, for creating a harmony between the physical and spiritual body, it is necessary to keep balance of six tastes in food: bitter, sweet, sour, viscous, salty and spicy. Due to the sauce for salads, which recipe is described in this work, the maximal balance of tastes in vegetable salads can be achieved. At that the minimal influence on the physical and mental human stability is preserved, because the introduction of natural aromatizers excludes a necessity to add spices that can break it.

\section{Conclusions}

There was conducted the study on creating the aromatic salad sauce vinaigrette. Fractions of lemon essential oil were used as a natural aromatizer. It allows to get two aromatizers with different smells of the same essential oil and to use them both in perfume-cosmetic means and food technologies. Different compositions and quantity ratios of fractions condition their different aromatic qualities: fraction of terpenes No. 1 has the lemon smell with a bergamot tint; fraction of terpenoids No. 2 - citrus smell with a flower tint. 
Investigating different amounts of the aromatizer, introduced in the salad sauce, by the sensor method, there were determined the smell intensity of the ready product and its organoleptic parameters. The curve, presenting organoleptic properties of dishes has a hyperbolic character and testifies that the optimal amount of introduction is $0,02 \%$ of the fraction No. 1 and $0,025 \%$ of the fraction No. 2 of lemon essential oil.

According to the results of the comparative profilogram of the smell of the ready product and aromatized sauces with introducing fractions of lemon essential oil, it has been established, that the introduction of natural aromatizers of lemon essential oil provides higher quality indices of aromatized products. Thus, it is possible to provide the complete independence of a dish on season and complete reproducibility of its smell. At that the use of essential oil fractions in culinary has a social effect, because favors cooking high-quality food products of natural raw materials.

It is expedient to continue the studies for joining ingredients of the aromatized sauce with different types of salads in the aspect of ayurvedic food. But it must be remembered, that natural aromatizers have limited storage terms (near 6 months) and need further studies.

\section{References}

[1] Morningstar, A. (1995). Ayurvedic Cooking for Westerners: Familiar Western Food Prepared with Ayurvedic Principles. Lotus Press, 395.

[2] Lad, V., Frouli, D. (2015). Travy i spetsii. Moscow: Sattva, Profil', 320.

[3] Frolova, N., Yushchenko, N., Sliusarenko, V., Avramenko, M., Luka, A., Piatyhorets, A. (2018). Development of technology of ayurvedic culinary products with natural plant components. Technology Audit and Production Reserves, 6 (3 (44)), 48-54. doi: https://doi.org/10.15587/2312-8372.2018.152736

[4] Sbornik receptur blyud i kulinarnyh izdeliy dlya predpriyatiy obshchestvennogo pitaniya (2011). Moscow, 336.

[5] Sylka, I., Frolova, N. (2015). Technology of natural flavours from home raw material and apparatus base. Novi rishennia v suchasnykh tekhnolohiyakh: Visnyk NTU "KhPI", 46. Available at: http:// dspace.nuft.edu.ua/jspui/handle/123456789/23482

[6] Aromatyzatory naturalni iz efirnykh olii. Tekhnichni umovy: TU U 24.6- 22961668-007:2007 (2007). Kyiv: Derzhspozhyvstandart Ukrainy, 15.

[7] Frolova, N. E., Ukrainets, A. I., Chepel, N. V., Sylka, I. M., Naumenko, K. A. (2009). Pat. No. 45835 UA. Process for preparation of caravay scents, natural flavoring agents. No. u200906561; declareted: 23.06.2009; published: 25.11.2009, Bul. No. 22.

[8] Kuzmin, O., Suikov, S., Niemirich, O., Ditrich, I., Sylka, I. (2017). Effects of the water desalting by reverse osmosis on the process of formation of water-alcohol mixtures. 1H NMR spectroscopy studies. Ukrainian Food Journal, 6 (2), 239-257. doi: https://doi.org/10.24263/2304-974x-2017-6-2-6

[9] DSTU ISO 6564:2005 (ISO 6564:1985, IDT). Doslidzhennia sensorne. Metodolohiya. Metody stvorennia spektra fleivoru (2006). Kyiv: Derzhspozhyvstandart Ukrainy, 9.

[10] Frolova, N., Ukrainets, A., Sylka, I., Naumenko, K., Chepel, N. (2017). Actuality and ways of processing lokal spicy-aromatic raw materials into food flavors. Scientific Works of National University of Food Technologies, 23 (5 (2)), 220-228. doi: https://doi.org/10.24263/2225-2924-2017-23-5-2-28 